\title{
Direct Arguments for the Truth-Condition Theory of Meaning ${ }^{1}$
}

\author{
William G. Lycan \\ University of North Carolina
}

1. Competition between philosophical theories of linguistic meaning is sometimes specious. For example, suppose Ned believes that an utterance's meaning is its truthcondition, while Ted insists that the utterance's meaning is constituted by the speaker's communicative intentions à la Grice. Here one wants to distinguish explananda: What Ned is after is really the utterance's ("timeless") sentence-meaning; Ted is focusing on speaker-meaning, which is not the same, and the two theories are perfectly compatible, indeed mutually complementary, accounts of distinct phenomena.

Or the dispute may prove to be verbal. Jed and Red agree that a sentence-token has both a truth-condition and an illocutionary force, but they disagree over which of those two features constitutes the sentence's meaning (italics original): Jed says the meaning is the truth-condition, force being important but merely pragmatic, while Red says the meaning is the force, truth-condition being important but merely the feature that determines the speech act's locutionary content. It would be hard to show that that disagreement is more than a schoolyard scuffle over who gets to keep the term. In such a dispute, each combatant tries valiantly to reserve and protect the buzzword "meaning" as attaching to what s/he feels is the more interesting and striking of the two features. Lycan (1984) offers the "Double Indexical" theory of meaning as the term is used in altercations of this kind: 
MEANING $=_{\text {def }}$ Whatever aspect of linguistic activity happens to interest $m e$ now. [p. 272]

Or a compatibility may simply go unnoticed. The classic Verificationism of the Positivists is universally thought of as a rival of the Truth-Condition theory. Yet-though I have never seen this so much as noted in print - the Verification theory is not only compatible with the Truth-Condition theory but entails it. For a Verificationist, a sentence's verification condition, besides being its meaning, is its truth-condition. To see this, consider a sentence to which the Verificationist would assign a meaning other than its face-value or ostensible meaning, such as a sentence about electrons; e.g., the Verificationist says, "An electron has just passed through the cloud chamber" means that having squeezed the bulb, one sees a trail of grey specks in the chamber, etc. Now, if a sentence means that $\mathrm{P}$, then that sentence is true iff $\mathrm{P}$. So on the Verificationist analysis, "An electron has just passed through the cloud chamber" would be true iff having squeezed the bulb, one sees a trail of grey specks in the chamber, etc.; thus the Verificationist theory assigns to that sentence, and to every other sentence to which it applies, a truth-condition, and in particular a truth-condition that according to the theory is the sentence's meaning. So, to put it provocatively: Verificationism $=$ the TruthCondition theory plus some distinctive advice about how to determine what a given sentence's truth-condition is (viz., by asking how the sentence is verified); the pure Truth- 
Condition theorist's complaint against the Verificationist is, at worst, that the advice is bad and that the Verificationist gets the truth-conditions wrong. ${ }^{2}$

Yet of course competition between theories of meaning is often real and substantive. Suppose, rather, that Ted does join Ned in pursuing timeless sentencemeaning, but that he follows Grice (1968) in arguing that sentence-meaning is not truthcondition at all, but a complex function of possible speaker intentions; then there is genuine disagreement. Or suppose that while Jed holds that illocutionary force is merely a pragmatic, psychological appendage to sentence-meaning (= truth-condition), Red insists that the truth-condition properly characterizes, not the sentence, but only the underlying propositional-attitude content that partly constitutes the force; genuine disagreement again, because Red and Jed have conflicting views of which feature is conceptually and/or explanatorily prior.

2. My concern in this paper is with sentence-meaning, and with a certain sort of argument for the Truth-Condition theory of sentence-meaning. The argument-call it the "Determination Argument"-is intended to establish that sentence-meaning is at least truth-condition, whether or not other features such as force (or "conceptual role" or implicatures) also deserve to be included as part of "meaning." In particular, I shall confront the argument with some objections suggested by recent "use" theories. A very compressed version of the Determination Argument is presented by David Lewis (1972): 
In order to say what a meaning is, we may first ask what a meaning does, and then find something that does that.

A meaning for a sentence is something that

determines the conditions under which the sentence is

true or false. It determines the truth-value of the sentence

in various possible states of affairs, at various times, at

various places, for various speakers, and so on. (p. 22)

Considered as a defense of the Truth-Condition theory, this passage is sketchy.

Indeed, it seems more a flat assertion than an argument, or at least to beg the question.

But now look carefully at its concluding sentence, and note that that sentence does not simply presuppose its predecessor. I read the concluding sentence as freestanding and as the argument's main premise. Let us reformulate it, concentrating on Lewis' notion of a "possible state of affairs."

He makes it clear that the possible states of affairs that chiefly concern him are whole possible worlds.

Contingent sentences depend for their truth value on facts about the world, and so are true at some possible worlds and false at others. A possible world corresponds to a possible totality of facts, determinate in all respects. (p. 
Lewis construes the idea of a meaning's determining a sentence's truth-value in settheoretic terms, and concludes that a meaning is (in part ${ }^{3}$ ) a function from possible worlds to truth-values.

Lewis' conception of a truth-condition is of course that which derives from Carnapian intensional logic. But not all truth-condition theorists work within that format. Some eschew the idea of a multiplicity of possible worlds. For example, Davidson (1965, 1967, 1973) exhibits a sentence's truth-condition merely as the right-hand side of the Tarski biconditional directed upon that sentence (e.g., "“Platypuses have webbed feet' is true iff platypuses have webbed feet"), the biconditional having been derived from a Tarskian truth theory for the containing language, and he keeps his treatment strictly extensional. I shall remain neutral both as between these two ways of representing truthconditions and also as between metaphysicians who think there is only one world and those who contend that there are many merely possible worlds as well as our actual one; so I shall pick up Lewis' phrase "a totality of fact," meaning roughly an entire world, and use it as neutrally as is convenient, though it will usually be most convenient to talk of multiple worlds. ${ }^{4}$

The argument's first premise is, then,

(1) A sentence's meaning taken together with a totality of fact determines the sentence's truth-value.

(One-worlders may substitute "the" for "a" in "a totality of fact.") 
The argument then proceeds as follows.

$\therefore$ (2) A sentence-meaning is at least a function from possible worlds to truth-values. ${ }^{5}$ [1]

(3) Such a function is a truth-condition. [As conceived in intensional $\operatorname{logic}]$

$\therefore$ (4) A sentence-meaning is at least a truth-condition. [2,3] QED

This argument has an epistemological version, given by Field (1977) and Lycan (1984), that is perhaps more intuitive:

(1-E) If you know a sentence's meaning and you are omniscient as regards fact, then you know the sentence's truth-value. [Seems obvious]

$\therefore$ (2-E) Knowing a sentence's meaning is at least knowing enough to assign the sentence a truth-value given a totality of fact. [1-E]

(3-E) To know enough to assign the sentence a truth-value given a totality of fact is to know a truth-condition. [Intensional logic again]

$\therefore$ (4-E) Knowing a meaning is at least knowing a truth-condition. [2-E,3-E] 
I must emphasize again that our conclusions (4) and (4-E) are compatible with "meaning"'s comprising more than truth-condition, say force as well. My quarrel will be only with those theorists who hold that meaning does not include truth-condition.

3. Let us consider some objections to these two versions of the Determination Argument. A first problem is that, if taken quite literally, (1-E) is trivially true and too weak to support (2-E): So long as "fact" includes linguistic fact, of course an omniscient being knows all sentences' meanings along with all the nonlinguistic facts. One of the facts that an omniscient being would know is that the sentence "Platypuses have webbed feet" means that platypuses have webbed feet, and another is that sentence's truth-value; so of course the omniscient being can "assign" the sentence a truth-value. But that does nothing to show that an ordinary person's knowledge of meaning requires the ability to assign truth-values, or that a meaning is the thing on the basis of which the truth-values are ordinarily assigned. Indeed, the same problem afflicts (1) in the original argument; a totality of all fact already includes both the sentence's meaning and the sentence's truthvalue, which (without question-begging) does nothing to show that the meaning is a function from worlds to truth-values.

One's first instinct is to qualify (1) and (1-E) by restricting "fact" to nonlinguistic fact; that is what I tacitly meant in first uttering (1) and (1-E), and most philosophers would not have thought of the present objection very soon. But such a restriction would falsify both those premises, since they would then not hold for metalinguistic sentences. 
One might know the meaning of "Die' is both a noun and a verb" and also know all the nonlinguistic facts, and still not know whether "die" is both a noun and a verb.

One's natural response is to go hierarchical, and supplement the restricted (1) and (1-E) with meta-metalinguistic clauses that do apply to metalinguistic sentences. But then, for just the same reason as before, one would have to restrict those clauses as applying only to first-order metalinguistic sentences, and so on up. Indeed, it looks as though a type theory is needed. We can amend (1) and (1-E) by implicitly quantifying over levels of the hierarchy, as in "For any sentence of level $n, \ldots$ totality of facts of all levels lower than $n, \ldots .$. I see no paradox or other objection to the potential regress suggested by this, and I shall say no more of the present issue.

A second objection is that the Determination Argument seems to apply only to declarative sentences. Imperatives and interrogatives, it is widely thought, do not have truth-values at all, yet (as the Positivists seem to have missed) they are every bit as meaningful as declaratives.

To this I reply that imperatives and interrogatives do have bipolar semantic values which might just as well have been called truth-values even though they normally are not. An imperative is obeyed or not (depending on whether its propositional complement turns out to be true or false) and a question has the correct answer "yes" or "no" (depending on whether its corresponding declarative is true or false). ${ }^{6}$ The custom of not calling nondeclaratives true and false is only that, a custom, and is expendable; without detriment 
to the language, we could have called imperatives "true" or "false" depending on their being obeyed, and questions "true" or "false" depending on their correct answers.

A third and more trenchant objection calls our attention to deixis: (1-E) is false, because if the sentence in question contains indexicals or other deictic items, one certainly can know its meaning, and be factually omniscient, and yet not know the sentence's truth-value. If we come into an empty classroom and find written on the blackboard, "I will be out of town tomorrow; class is postponed until Tuesday during your normal lab hour," even (nonlinguistic) factual omniscience will not deliver that sentence's truth-value; we would need to find out who had written it and when and to whom. The same point can be made against (1).

This is just the same complication for truth-conditional semantics as was noted by Kaplan (1977), following Frege, and it should yield to his strategy of distinguishing a sentence's "character" from the sentence's "content." Content is what we have heretofore been calling "meaning," on the truth-conditional view a set of worlds or a function from worlds to truth-values. Actual content is what is left undetermined by the anonymous sentence in our example. Character is what does determine content given all the relevant features of a context of utterance: Faced with our indexical sentence and once given utterer, hearer, date, and and time, a competent speaker of English would immediately work out its content. Thus, character is a function from contexts to contents. Kaplan argues that the "m"-word should be reserved for character rather than for content, on the entirely reasonable ground that ordinary English speakers surely know the 
meanings of everyday indexical sentences even when they do not know the values of the contextual parameters that fix the contents of those sentences' particular tokens. In this sense, then, (1) and (1-E) are still false, for "meaning" in the sense of character.

I would contend that (1) and (1-E) are not entirely wrong. Despite Kaplan's argument, content in his sense is still a perfectly good thing to mean by "meaning." Note that although in the one way we know the meaning of the sentence on the blackboard, in another way we do not: We do not know what its utterer actually said. In traditional terms, we do not know what proposition the token expresses. And in this sense, so far as has been shown, (1) and (1-E) are still true, and the original arguments stand.

Moreover, "meaning" in the sense of character is still closely tied to truthcondition, for a character is simply a function from utterance context to "meaning" in the sense originally intended. And, so to speak, its whole point is to be that: Until character has done its job by having a full set of contextual features plugged into it, no assertion can be made and no communication can take place. ${ }^{8}$

Nonetheless, recognizing the naturalness of Kaplan's preferred usage, I concede the following modifications for the case of "meaning" in his sense:

(1+) A sentence's meaning taken together with a context of utterance and a totality of fact determines truth-value.

$\therefore(2+)$ A meaning is at least a function from contexts of utterance to functions from possible worlds to truth-values. 
(3) A function from worlds to truth-values is a truth-condition.

$\therefore$ (4) A sentence-meaning is at least a function from contexts of utterance to truth-conditions. $[2+, 3]$

(1-E+) If you know a sentence's meaning and you know all the truthrelevant features of the sentence's context of utterance and you are omniscient as regards fact, then you know the sentence's truth-value in the context.

$\therefore(2-\mathrm{E}+)$ Knowing a sentence's meaning is at least knowing enough to assign the sentence a truth-value given a context and a totality of fact.

(3-E+) To know enough to assign the sentence a truth-value given a context and a totality of fact is to know (at least) a truth-condition for an utterance of that sentence in that context.

$\therefore$ (4-E+) Knowing a meaning is at least knowing (at least) a truth-condition in a context. [2-E+,3-E+]

For all the objection has shown, this treatment is adequate. 
4. Against what rivals does the Truth-Condition theory need defending, in the early twenty-first century? Few philosophers of language currently champion a verificationist theory of sentence-meaning, or illocutionary theories like Alston's (1963, 2000), or Grice's (1968) program based on speaker-meaning. ${ }^{9}$ Currently vital competitors seem to be "use" theories of various kinds: "Conceptual role" accounts as advocated by Harman $(1974,1975,1982),{ }^{10}$ the more radical inferentialist program of Brandom $(1983,1994,2000)$, and the more primitive view taken by Horwich (1990, 1999, 2005). There is a variety of ideas clustered in this region. For convenience I shall lump them together and call them just, crudely, "Use" theories.

The general idea of "Use" theories is that linguistic expressions are like chess pieces or other game tokens, in that they are deployed in obedience to certain distinctive social norms. A given expression is appropriately tokened in response to this or that circumstance (linguistic or nonlinguistic); its tokening demands or at least licenses further utterances by the speaker and/or the audience; some utterances require or license nonlinguistic acts. The norms governing all this activity are of course conventional, since any word could have been used to mean something other than what it does mean. (But they are not merely, or capriciously or frivolously, conventional. The whole gigantic system of conventions that is a human natural language has evolved and refined itself over centuries, in response to pragmatic pressures of many sorts, and no doubt has features that are indispensable given the ways in which we are situated in the world and what Wittgenstein called our "forms of life." 
So far, of course, the Truth-Condition theorist need raise no objection. (Indeed, s/he had better not, for what we have so far attributed to "Use" theories are obvious truths.) Rather, the dispute comes when the "Use" theorist adds that a linguistic expression's meaning is simply and exhaustively constituted by the expression's normative role in the giant game-like social practice that is the shared language of a speech community, and that in particular there is no need to advert to truth-conditions or (on some views) even to word-world reference in order to explain the things that theories of meaning are charged with explaining. As I have said, our Truth-Condition theorist does not insist that truth-condition suffices for "meaning," but s/he does insist that truthcondition is necessary, and that is what the "Use" theorist denies.

This means that in particular, the "Use" theorist must resist our Lewisian argument in both its original and its epistemological versions. It is far from obvious how s/he might do that. Which of the premises would naturally be denied by someone taking the "Use" point of view? A radical Wittgensteinian who recognized only such primitive types of use as in his opening builders' game (“Slab!") might deny the argument's opening premise, $(1+)$ or (1-E+) as it might be, contending that meaning in this merely behavioristic sense has nothing to do with the checking of sentences against facts. Compare examples of purely ritual utterances: "Hello," "Damn," "Ouch," "Ha ha," “"Scuse me," "Thanks," "Shame!," "Fore!” and the like. These are the Wittgensteinian's paradigm. 
It is tempting for the Truth-Condition theorist to reply that that is the trouble with Wittgensteinian "Use" theories. Such ritualistic utterances are rare exceptions in real discourse and should not be taken as paradigmatic; grammatically, they are not even complete sentences.

The grammatical slur is unpersuasive, for arguably some such expressions are complete sentences in that they have understood, ellipsized subjects and predicates"[God/I] damn [this/that]," “(Please would) [you] excuse me?," "[I] thank [you]," etc. I think the critical point is better made in Austinian terms of illocutionary force and locutionary content: The vast majority of utterances have both force and content. Granted, there are exceptions on each side. An English sentence shouted across a canyon to test the echo may have a content but no force; it is not being used to perform any illocutionary act. Purely ritual expressions such as those listed above have (obvious) forces but no locutionary contents. ${ }^{11}$ But Truth-Condition theories of meaning are really theories of locutionary content, and do not purport to be theories of force; so it is no embarrassment to them that there are a few types of utterance that have forces but no contents.

Thus, (1+) and (1-E+) are safe from the radical Wittgensteinian. But what about forces other than the assertive? ${ }^{12}$ Must not (1+) and (1-E+) be modified to accommodate those? No, because in response to the second objection considered in section 3, I have already verbally expanded the notion of "truth-value" to cover the bipolar values we attach to speech acts of kinds other than the assertive. 
In any case, current "Use" theorists such as those listed above are not radical Wittgensteinians, precisely because they do deal primarily and squarely with normal utterances that have locutionary contents. But they thereby incur a greater difficulty in resisting the Lewisian argument.

5. To appreciate the problem, consider: Suppose a certain community agrees to use certain words — or at any rate sounds and marks — in a peculiar way; e.g., they decide to put only "words" with the same number of syllables next to each other in threes, or they utter "sentences" only in rhyming pairs, where each string begins with a one-letter grapheme and adds one letter successively to each ensuing item. (This might be a sort of community-wide parlor game.) If someone happened upon this whimsical society and knew nothing of the arrangement, s/he would not understand what was going on. S/he might, in time, if s/he were an acute observer, make out all the rules according to which the various tokens were being used, and yet the sense of the whole arrangement might remain entirely obscure to her/him; s/he might have no notion what, if anything, was being said. S/he might then suspect that s/he has only been watching a game.

In fact, let us cast this sort of thought-experiment in a more refined form. Our general question is that of how the "Use" theorist might go about distinguishing genuine language use from other, but nonlinguistic, rule-governed social practices such as games in the ordinary sense. Now, suppose we have a bunch of colored placards, some of which have various designs on them, squiggles of various characteristic shapes. ${ }^{13}$ Nothing very elaborate; perhaps each of us has been issued a set of ten placards. Suppose further that 
we just make up some simple, stupid little rules for manipulating these squiggles. For example, when the leader holds up the red placard with the thing that looks like the Greek letter $\pi$ on it, everyone is to shout out the sound "froop" and pass one placard to the left. (After a short while, what with that rule and others, we will not all have just the same cards.) And when anyone spontaneously holds up any yellow card, the player directly opposite must hold up any of the blue ones. When an even number of people are holding up cards bearing hexagons, anyone on the side of the room opposite the leader who has any yellow card must pass it to the right. But if one receives a yellow card with the squiggle that looks like a snake on it, s/he must shout out "crabgrass" and bang the table twice, and anyone whose surname has at least seven letters should say "septosieben" and either raise a red card or run down the hall and back again. And so on. Though it sounds like Twenty-Three-Man Squamish or some other Mad magazine fantasy, we could quite feasibly play the game, according to the set of conventional rules that we have all agreed to for manipulating the placards.

Now of course the point is that so far, the placard game is just a game. There are the tokens and our conventional rules for manipulating them, but as yet, none of this looks at all like a genuine language.

One clear sense in which a social practice qualifies as an actual language is that, according to it, one can make noises or inscribe marks and thereby say that $P$ for some suitable sentence replacing ' $\mathrm{P}$ '. And one of the things that is essential to language is that we can say things in it. (More on this below.) 
The point can be made using far less fanciful examples, indeed examples of real games such as chess and tennis. To move N-Q3, or to return a serve to the server's backhand, is not (literally) to say that anything or to ask whether anything or to advise anyone to do anything. Similarly, my point about the placard game is that so far as I can see, no indirect discourse is licensed just in virtue of some people's playing the game; no one has said or asked or requested or suggested...that anything at all. It seems there is something missing. We are playing a game, and using tokens according to a set of conventional rules, and engaging in a social practice that may not only be fun but have some larger point; it might even be in some way vital to our way of life. Yet nobody has said anything. The things the players in these various games have done may have significance in some sense, but nobody has made any assertions or performed speech acts of any other kinds. The moves in these games do not have meanings in the linguistic sense. (Contrast the case where spies are using chess moves as an actual secret code; e.g., $\mathrm{N}-\mathrm{Q} 3$ may have conventionally been stipulated to mean "Take the zircon to Foppa and tell him we move tonight.")

At this point we must distinguish two possibilities, and turn the present argument into a dilemma. The placard game is importantly underdescribed, with respect to the vital concern of truth-conditions. For someone might argue that if its rules are rich enough and advert often enough to ambient conditions, reference and predication will be recoverable from the game description. E.g., suppose there is a rule that whenever the waiter comes in, each player holding a card inscribed with a martini-glass shape shouts "Here, waiter," 
and is given a martini; whenever anyone sees a robin out the window, s/he says "Look, nobir!" and everyone else exclaims "Ahhh"; whenever a player says "Mix please," s/he is passed the bowl of snacks by whomever is nearest it; and more in this vein. One would then be tempted to conclude that the glass shape stands for martinis, "waiter" refers to the waiter, "nobir" means robin or at any rate bird, and "mix" means snack food. In that case, the placards and vocal utterances specified by the game rules would have meanings, and (I would say, in virtue of) truth-conditions.

In order to set up our dilemma we need not linger over the theory of reference and decide what exactly it would take for the placards or utterances to have referential truthconditions. I require only the disjunction: Either the game moves do have truthconditions or (by stipulation) they do not. Call the first scenario the "Impure Placard Game" and the second the "Pure Placard Game." Then I argue as follows. Moves in the Impure Game are meaningful linguistic utterances, but only because they have truthconditions. Moves in the Pure Game are not meaningful linguistic utterances. ${ }^{14}$

The latter assertion should be obvious, once we have stipulatively removed the natural temptation to read reference and truth into the game moves. ${ }^{15}$ Once carefully distinguished from the Impure Game, the Pure Game does not seem to be even the beginning of an actual language, in particular because it does not exemplify a crucial aspect of language: reportability in indirect discourse. So we have a counterexample to "Use" theories. The "Use" theorist's conditions are not sufficient for something's being a language. 
Now, then, consider a theory of meaning, $\mathcal{T}$, that ostensibly competes with the Truth-Condition theory.

(B1) Either $T$ tacitly incorporates truth-condition and adds something else [“conceptual role," force, verification-condition, implicatures,...] or T does not.

(B2) If $\mathcal{T}$ does incorporate truth-condition, then $\mathcal{T}$ is not after all a competitor of the Truth-Condition theory; further dispute is verbal.

(B3) To be correct, $\mathcal{T}$ must rule out the Pure Placard Game.

(B4) If $\tau$ does not incorporate truth-condition, then $\tau$ must rule out the Pure Game in some other way.

(B5) It is hard to think of any other adequate way of ruling out the Pure Game.

$\therefore$ (B6) For any competitor of the Truth-Condition theory, it is hard to think how that competitor could be correct. [B1-B5]

Moreover, 
(C1) To rule out the Pure Placard Game, one must provide means whereby a speaker can produce a token meaning that so-and-so (thereby asserting that so-and-so or asking whether such-and-such or...).

(C2) Any token (structured or unstructured) that means that P, for any P, is a sentence.

(C3) A sentence means that $\mathrm{P}$ only if the sentence is true iff $\mathrm{P} .{ }^{16}$

(C4) A sentence that is true iff $\mathrm{P}$ has a truth-condition.

$\therefore$ (C5) To rule out the Pure Game, one must provide means for endowing a speaker's utterances with truth-conditions. [C1-C4]

6. The anti-Verificationist argument of section 1 may seem to generalize fast: "If a sentence means that $\mathrm{P}$, then that sentence is true iff $\mathrm{P}$. So on the Blah-Blah theory of meaning, 'An electron has just passed through the cloud chamber' would be true iff [whatever the Blah-Blah-ist theory says that sentence means]; thus the Blah-Blah-ist theory assigns to that sentence, and to every other sentence to which it applies, a truthcondition, and in particular a truth-condition that according to the theory is the sentence's meaning. So, to put it provocatively, Blah-Blah-ism $=$ the Truth-Condition theory plus some distinctive advice about how to determine what a given sentence's truth-condition is (though that advice may be bad, as we complained against the Verificationist)." 
Now, the Verification theory has been a somewhat special case in this discussion, because that theory triggers my assumption (C3) that if a sentence means that $\mathrm{P}$, then the sentence is true iff $\mathrm{P}$. That in turn is because the Verification theory delivers meaning specifications for particular sentences that are couched in terms of "that"-clauses; a verification condition can itself be so complementized. ${ }^{17}$ Other theories lack the latter virtue; they do not show how to get from a specification of a sentence's "use" (or whatever) to a "means that" clause--and so those theories fall afoul of argument (C1)(C5).

So the Verification theory is adequate only because it does deliver "means that" clauses, and no theory that fails to do the same is adequate. What the relevantly adequate theories have distinctively in common is that they do trigger (C3). And that encourages Davidson's famous semi-rhetorical question: What does "means that" add to "is true iff" in the latter's stronger-than-truth-functional sense? Absent a convincing answer, we should conclude that it is after all the sentence's truth-condition that is doing the work of being the sentence's meaning; that the truth-condition might also be the verification condition is incidental.

But might there not be a convincing nonrhetorical Verificationist answer? (I continue to discuss Verificationism here rather than "Use" theories because it does without question deliver "means that" clauses. If a particular "Use" theory also delivers them, then what follows should apply to it as well.) Such an answer, so far as I can see, would have to take one of three forms: (i) to show that verification has a specifically 
meaning-explanatory role to play, which role is not fulfilled by truth alone; (ii) to show that truth is problematic in a way that verification is not; or (iii) to show that truthconditions themselves are philosophically reducible to verification conditions. Let us consider each of these options briefly in turn.

(i): It is sometimes complained against Truth-Condition theories that they divorce meaning from epistemology. No such complaint could be made against the Verificationist, whose theory reduces meaning precisely to epistemology.

But what legitimizes the complaint in the first place? What did the epistemologizing of meaning explain that Truth-Condition theories do not? There is no obvious candidate. (One putative explanandum would be the alleged normativity of meaning: if meaning is normative, the Verification theory is well positioned to explain that, by reference to the underlying epistemic norms. But (a) it is hardly obvious that meaning is at all normative; those who contend that meaning is normative tend to be those who already hold an epistemic theory of meaning. And (b) I suspect that for any argument purporting to show that meaning is normative, a parallel argument would show that truth is normative also, thus depriving the Verificationist of the advantage there. ${ }^{18}$ )

(ii): I know of two attempts to argue that truth is problematic in a way that verification is not: Michael Dummett's $(1959,1975,1976)$ well-known case against the idea of allowing verification-transcendent truth-conditions into one's theory of meaning; and objections arising from recent deflationism about truth (e.g., Brandom $(1983,1994)$; Horwich (1990, 1999)). 
On each of these points, I can only refer the reader to other works of mine. Lycan (1984, pp. 248-57) rebuts Dummett's case at length. Bar-On, Horisk and Lycan (2000) consider four deflationism-based objections to the Lewisian argument in particular, and find each entirely unconvincing. ${ }^{19}$ We conclude that either deflationism is compatible with the Truth-Condition theory, ${ }^{20}$ or deflationism is false (because incompatible with the unrefuted Lewisian argument's conclusion).

(iii): If truth-conditions are reducible to verification conditions, then one might insist that although sentence meanings are (indeed) truth-conditions, those are in turn verification conditions, and so what sentence meanings are at bottom is verification conditions. (Strawson (1970) took just this line except on behalf of Grice rather than Verificationism, maintaining that although it is fine or at any rate harmless to say that a sentence's meaning is the characteristic condition under which the sentence is true, the sentence's being true can be understood only in terms of its being used to say something true, and saying must be understood in Gricean terms of communicating the contents of underlying propositional atttitudes.)

I balk at the assumption that the transitivity of reduction renders the first stage of a two-stage reduction uninteresting or unimportant. Suppose, e.g., that knowledge is reduced to a causal relation of a certain kind. If causality is then reduced to something else, say to counterfactual relations, or to transfer of energy, that does nothing to diminish the epistemologist's achievement in having reduced knowing to causality. Similarly, 
should truth-conditions prove reducible to verification conditions, that would take nothing away from the accomplishments of the Truth-Condition theory of meaning.

I conclude that our refined version of Lewis' argument succeeds, and accordingly that linguistic meaning is at least truth-condition; any theory of meaning that rejects truthconditions must itself be rejected. 


\section{References}

Alston, W. (1963). “Meaning and Use,” Philosophical Quarterly 51: 107-24.

Alston, W. (2000). Illocutionary Acts and Sentence Meaning. (Ithaca, NY: Cornell University Press.)

Bar-On, D., C. Horisk and W.G. Lycan (2000). "Deflationism and the Truth-Condition Theory of Meaning," Philosophical Studies 101: 1-28. Reprinted with substantive "Postscripts" in Beall and Armour-Garb (2005).

Beall, JC, and B. Armour-Garb (eds.) (2005). Deflationary Truth. (Chicago: Open Court Press.)

Brandom, R. (1983). “Asserting,” Noûs 17: 637-650.

Brandom, R. (1994). Making It Explicit. Cambridge, MA: Harvard University Press.

Brandom, R. (2000). Articulating Reasons: An Introduction to Inferentialism. (Cambridge, MA: Harvard University Press.)

Carnap, R. (1947). Meaning and Necessity. Chicago: University of Chicago Press.

Cohen, L.J. (1964). “Do Illocutionary Forces Exist?,” Philosophical Quarterly 14: 11837.

Cresswell, M.J. (1972). “The World Is Everything That is the Case,” Australasian Journal of Philosophy 50: 1-13.

Cresswell, M.J. (1973). Logics and Languages. (London: Methuen.)

Cresswell, M.J. (1985). Structured Meanings. (Cambridge, MA: Bradford Books / MIT Press.) 
Cresswell, M.J. (1990). Entities and Indices. (Dordrecht: Kluwer Academic Publishing.)

Cresswell, M.J. (1996). Semantic Indexicality. (Dordrecht: Kluwer Academic Publishing.)

Davidson, D. (1965). "Theories of Meaning and Learnable Languages,” in Y. Bar-Hillel (ed.), Proceedings of the 1964 International Congress for Logic, Methodology, and Philosophy of Science. (Amsterdam: North-Holland.)

Davidson, D. (1967). “Truth and Meaning,” Synthese 17: 304-23.

Davidson, D. (1973), "In Defense of Convention T," in H. LeBlanc (ed.), Truth, Syntax and Modality. (Amsterdam: North-Holland.)

Davidson, D., and G. Harman (eds.) (1972). Semantics of Natural Language. (Dordrecht: D. Reidel.)

Dummett, M. (1959). “Truth,” Proceedings of the Aristotelian Society 59: 141-62.

Dummett, M. (1975). "What Is a theory of Meaning?," in S. Guttenplan (ed.), Mind and Language. (Oxford: Oxford University Press.)

Dummett, M. (1976). "What Is a theory of Meaning, II," in Evans, G., and J. McDowell (eds.), Truth and Meaning. (Oxford: Oxford University Press.)

Field, H. (1977). “Logic, Meaning, and Conceptual Role,” Journal of Philosophy 74: $379-409$.

Grice, H.P. (1968). “Utterer's Meaning, Sentence-Meaning, and Word-Meaning," Foundations of Language 4: 225-42. 
Harman, G. (1974). “Meaning and Semantics,” in M. Munitz and P. Unger (eds.), Semantics and Philosophy. (New York: New York University Press.)

Harman, G. (1975). "Language, Thought, and Communication," in K. Gunderson (ed.), Language, Mind, and Knowledge. (Minneapolis: University of Minnesota Press.)

Harman, G. (1982). “Conceptual Role Semantics,” Notre Dame Journal of Formal Logic 23: $242-256$.

Horwich, P. (1990). Truth. (Oxford: Oxford University Press.)

Horwich, P. (1999). Meaning. (Oxford: Oxford University Press.)

Horwich, P. (2005). Reflections on Meaning. (Oxford: Oxford University Press.)

Kaplan, D. (1977). “On the Logic of Demonstratives,” in P. French, T.E. Uehling and H. Wettstein (eds.), Contemporary Perspectives in the Philosophy of Language. (Minneapolis: University of Minnesota Press.)

Lewis, D. (1972). “General Semantics,” in Davidson and Harman (1972).

Lycan, W.G. (1984). Logical Form in Natural Language. (Cambridge, MA: Bradford Books / MIT Press.)

Lycan, W.G. (1991). Review of Anita Avramides' Meaning and Mind, Mind and Language 6: 83-86.

Lycan, W.G. (1994). Modality and Meaning. (Dordrecht: Kluwer Academic Publishing.) Lycan, W.G. (2000). Philosophy of Language. (London: Routledge.)

Montague, R. (1968). “Pragmatics," in R. Klibansky (ed.), Contemporary Philosophy: A Survey. (Firenze: La Nuova Italia Editrice.) 
Patterson, D. (2007). "On the Determination Argument Against Deflationism," Philosophy and Phenomenological Research :--

Sadock, J.M. (1985). "On the Performadox, or A Semantic Defense of the Performative Hypothesis," University of Chicago Working Papers in Linguistics, Vol. I: 160-69. (Chicago: University of Chicago Department of Linguistics.)

Scott, D. (1970). “Advice on Modal Logic,” in K. Lambert (ed.), Philosophical Problems in Logic. (Dordrecht: D. Reidel.)

Searle, J. (1979). “A Taxonomy of Illocutionary Acts," in Expression and Meaning. (Cambridge: Cambridge University Press.)

Sellars, W. (1963). "Some Reflections on Language Games," in Science, Perception, and Reality. (London: Routledge and Kegan Paul.)

Sellars, W. (1967). Science and Metaphysics. (London: Routledge and Kegan Paul.)

Sellars, W. (1969). "Language as Thought and as Communication," Philosophy and Phenomenological Research 29: 506-27.

Stalnaker, R. (1968). "Pragmatics," in Davidson and Harman (1972).

Strawson, P.F. (1970). Meaning and Truth. (Oxford: Oxford University Press.) 


\title{
Footnotes
}

\begin{abstract}
${ }^{1}$ This paper was solicited and originally written for the Festschrift for M.J. Cresswell (Festschrift for Max Cresswell on the Occasion of His 65th Birthday, Logique et Analyse, Vol. 46, No.181 (2003)). The paper was duly submitted and accepted by the editors; but through some extraordinary screwup in press, it was omitted from the volume. I take the opportunity here to say what I would have said in my title footnote there: "Max Cresswell combines three great professional talents (I pass by his notable gifts as a stage actor): He is, of course, an accomplished logician; he has a linguist's ear for data and for verbal nuances; and, most importantly to me, he is a fine and acute philosopher, in any area of philosophy, on any topic, at any time."
\end{abstract}

${ }^{2}$ The Verificationist may protest that there is still a question of explanatory priority; is the verification condition the meaning only because it is also the truth-condition, as I have implied, or is the truth-condition the meaning only because it is the verification condition? I shall address this in section 6 below.

${ }^{3}$ Departing from Carnap (1947), whose sentence intensions were simply functions from worlds (or rather, their state-descriptions) to truth-values, Lewis follows Montague (1968) and Scott (1970) in treating his intensions as functions from "indices" to truth-values, an index being an $n$-tuple containing not only a world but a number of contextual features such as speaker and time, in addition. This practice is criticized, effectively in my view, by Stalnaker (1968), who urges the two-stage determination process now associated with Kaplan (1977): The contextual features 
determine a Carnapian intension, and the latter intension given a world determines a truth-value. Cresswell $(1972,1973)$ sides with Stalnaker in this. (Actually his way of representing the dependence of extension on context is elaborate and rigorous: "Contexts" are construed as propositions stating facts about particular uses of sentences, and functions are defined from such propositions to the extensions of the various sorts of indexical terms. For later and more subtle work on indexicality, see Cresswell $(1990,1996)$.

${ }^{4}$ For discussion of the ontology of possible worlds, see Lycan (1994).

${ }^{5}$ Alternatively, just a set of worlds, corresponding to the traditional notion of a proposition. I here ignore issues of intensional isomorphism and hyperintensionality; on those, see Cresswell (1985).

${ }^{6}$ This of course ignores $w h$-questions, but $w h$-questions have true or false answers depending on the singular term that gets plugged into their matrices. For example, "Who robbed the diaper service?" generates the answer-class \{“Alice robbed the diaper service," "Bob robbed the diaper service,"...\}, and is correctly or incorrectly answered by a member of that class accordingly as that member is true or false. In like wise, "When is the meeting?" generates \{“The meeting is at 1:00 p.m.," "The meeting is at 1:01 p.m.,"... . And intuitively, the meaning of a wh-question is parasitic on the meanings of its admissible answers.

${ }^{7}$ Of course, the term "truth-condition" itself can also be used in a way corresponding to Kaplanian character, as in fact by Davidson (1967) and Lycan (1984, Ch. 3). 
${ }^{8}$ Though it must be conceded to inferentialists and some other "use" theorists that sentences containing indexicals have perfectly clear patterns of inferential relations, e.g., from "You gave me that book" to "You gave me a book," "Someone gave me that book," etc.

${ }^{9}$ Remember that here it is sentence-meaning we are discussing; the plausibility of Grice's (1969) analysis of speaker-meaning itself is beside the point. (For objections to the Gricean theory of sentence-meaning, see Lycan (1991), but for a possible Gricean version of the Truth-Condition theory, see Lycan (2000, pp. 145-46).)

${ }^{10}$ The view, self-consciously formulated, originated with Sellars $(1963,1967,1969)$, though it owes debts to the later Wittgenstein and to Carnap.

${ }^{11}$ Notoriously, Lewis (1972:209) suggested that they do: he proposed to understand "Hooray for Porky" as "I cheer Porky." (Perhaps "Hello" means "I greet you," "Shame!" means "I castigate you" and "Damn!" means "I curse.")

Whether or not we are attracted to Lewis' view of the brief ritual utterances, Jonathan Cohen (1964) raised an enduring problem about the truth-conditions of explicit performatives: Is "I state that I have never seen this man before" true iff the speaker has never seen the demonstrated man before, or iff the speaker does so state? There are powerful arguments on each side. Cresswell (1973, Ch. 14) defends the initially less plausible second view, but tries to make it palatable by adding that a speaker's tokening the sentence in an appropriate context "conventionally counts as" asserting simply that s/he has never seen the man before; see also 
Sadock (1985). After resisting this view for some years, I have come to accept a version of it (Lycan (1984, pp. 142-54; 2000, p. 184)).

${ }^{12}$ The taxonomic term "assertive" is Searle's (1979). The illocutionary category of assertives includes "most of Austin's expositives and many of his verdictives as well" (p. 13).

${ }^{13}$ A quicker version of the following argument was given in Lycan (1984, pp. 244-46) and in Lycan (2000, pp. 95-97).

${ }^{14}$ It would take scholarship and thought to place Brandom on one horn or the other.

Horwich $(1998,2005)$ offers an interesting contrast, though his view is less well worked out. Unlike Brandom, he emphasizes that individual expressions have meanings: a given expression's "meaning property" is "its use being governed by such-and-such regularity—or, more specifically, the property that every use of the word is explained in terms of the fact that we accept certain specified sentences containing it" (1998, p. 6, italics original). For each word, there is a "basic use regularity." (Examples: We tend to accept "That's red" (if it is actually uttered) in the presence of a red thing; we accept " $p$ and $q$ " iff we accept " $p$ " and we accept " $q$. .") But, n.b., "accepting" a sentence is a psychological notion (pp. 94-96), rather than any form of actual social behavior; this is another departure from Wittgenstein and from Brandom. I suspect that Horwich's view covertly introduces reference by way of the aboutness involved in the relevant mental contents; but as in Brandom's case, for present purposes we need not decide this. My argument being a dilemma, it does not matter which horn is actually grasped by any of its targets. 
${ }^{15}$ Often when I have presented this placard-game argument to students, they have tried to find propositional meaning even in chess moves and tennis shots-suggesting; e.g., that a serve means (says!) "Hit this back to me if you can" and that its return means (asserts) "I'm as good as you, sucker." I think this is fanciful at best, but more importantly it is beside the point, if what is in question is the necessity of truth-condition for linguistic meaning.

${ }^{16}$ I take this premise to be true, indeed trivial, as it stands, not question-begging or even contentious, even though the "iff" is stronger than truth-functional. (C3) alone does not entail that what it is for the sentence to mean that $\mathrm{P}$ is for it to be true iff $\mathrm{P}$.

${ }^{17}$ I used to formulate this comparative virtue of the Verification theory by saying that it tells us, not just what meaning is tout court, but the particular meanings of particular sentences, which could then be specified using "that"-clauses (Lycan. (2000, p. 118). But that formulation was inaccurate. The Verification theory does not by itself tell us the meanings of particular sentences, any more than does a "Use" theory, because to get such a meaning one has to fill in one's own opinion as to what a given sentence's verification condition is. (I waive the Quinean point that particular sentences do not even have belief-independent verification conditions.) The point is rather that, no matter what one thinks is the verification condition of a given sentence, that condition will immediately deliver a "that"-clause.

${ }^{18}$ Someone might further suggest that Verificationism explains entailment facts better than does the Truth-Condition theory. According to the latter, a sentence $S_{1}$ entails another $S_{2}$ because $S_{2}$ 
is derivable (in Tarskian style or in possible-worlds semantics as the case may be) from $\mathrm{S}_{1}$ taken together with the two sentences' containing truth-conditional semantics. But is it not a deeper and better explanation to connect entailment to epistemology, by saying that any set of observations that verifies $S_{1}$ also verifies $S_{2}$ ?

I think not—because it seems to me that the reason any set of observations that verifies $S_{1}$ also verifies $S_{2}$ is that $S_{1}$ entails $S_{2}$, not the other way around.

${ }^{19}$ Two are especially worth mentioning. First, the deflationist may say that although meaning and fact "jointly" determine a sentence's truth-value, this is for a trivial and degenerate reason: that truth-value is already determined by fact alone; since the sentence's meaning is not involved in doing the determining, then either the inference from (1) to (2) is fallacious, or (3) is disputable. To that we replied that even if deflationism holds, it simply does not follow that truth-value is determined by fact alone without regard to the sentence's meaning.

Second, the deflationist may contend that to establish the full-blooded Truth-Condition theory, one needs to show more than that all meaningful sentences have truth-conditions. One has to show that truth-conditions are what (partly) explain what it is for a sentence to have its meaning, which would require assigning truth an explanatory role, which in turn would be to abandon deflationism about truth. We replied without taking a stand on that last premise (that to assign truth any explanatory role is to abandon deflationism): Truth plays several explanatory roles in regard to meaning; whether that means we must reject deflationism is a disputed question.

A third objection has been offered by Patterson (2007). It makes a subtle point about the nature of definitions; I shall not address that point here, because I think its target is a stronger 
claim than the one I, at least, meant to make in Bar-On et al. (2000). However, Patterson implies a more straightforward criticism of the Determination Argument, one which has also been put to me by Ted Parent and others: The move from (1) to (2) is not strictly valid. A brick taken together with a possible world determines the brick's color (if any) at that world, but we should not conclude that a brick is at least a function from worlds to colors. (A brick is not any type of function, not even one with a concrete appendage.) —Right; I think I must swallow that. Rather, I should say, (2) is merely the obvious explanation of (1), given that the sentence meanings we are talking about are abstract entities in the first place.

${ }^{20}$ Against received wisdom, which is incompatibilist on this point. Bar-On and Horisk are incompatibilists, while I am a compatibilist; see our respective Postscripts in Beall and ArmourGarb (2005). 